U.S. DEFARTHENT OF HEALTH, EDUCATIOM, AND WELFARE

CENTER FOR DISEASE CONTROL

NATIONAL INSTITUTE FOR OCCUPATIONAL SAFETY AND HEALTH

CINCINNATI, OHIO 45202

HEALTH HAZARD EVALUATION DETERMINATION

REPORT NO. 74-118-218

GENERAL TIRE \& RUBBER COMPANY

MARION, INDIANA

AUJUST 1975

I. TOXICITY DETERMINATION

It has been determined that airborne concentrations of toluene2,4,- diisocyanate (TDI) are potentially toxic to employees at the foam line in the Slab Department. The concentrations of TDI are not found to be toxic at the concentrations measured in the Molded Foam Department during normal operating conditions. However, particles of the mold release wax (MRW) were found to cause temporary irritant symptoms among some of the Pad Pullers. Exposure to polyvinyl chloride resins is not believed to pose a health hazard to employees in either of the two departments under worksite conditions which were observed at the time of this evaluation.

These determinations are based upon environmental measurements, medical interviews with employees, pulmonary function tests, and observation of work practices and engineering controls.

Recommendations have been offered in the body of the report for control of environmental exposure of employees to the potentially toxic substances and for medical surveiliarice of exposed employees.

II. DISTRIBUTION AND AVAILABILITY OF DETERMINATION REPORT

Copies of this Determination Report are available upon request from the Hazard Evaluation Services Branch, NIOSH, U.S. Post Office Building, Room 508, Fifth and Walnut Streets, Cincinnati, Ohio 45202. Copies have been sent to:

A. General Tire \& Rubber Company, Marion, Indiana

B. Authorized Representative of Employees

C. U. S. Department of Labor - Region V

D. NIOSH Regional Consultant - Region $V$

For purposes of informing the approximately 50 "affected employees" the employer will prompt1y "post" the Determination Report in a prominent place(s) near where affected employees work for a period of 30 calendar days. 
Page 2 - Health Hazard Evaluation Determination 74-118

III. INTRODUCTION

Section 20(a) (6) of the Occupational Safety and Health Act of 1970 , 29 U.S.C. $669($ a) (6), authorizes the Secretary of Health, Education, and Welfare, following a written request by any employer or authorized representative of emplovees, to determine whether any substance normally found in the place of employment has potentially toxic effects in such concentrations as used or found.

The National Institute for Occupational Safety and Health (NIOSH) received such a request from an authorized representative of employees regarding exposure of production workers to toluene diisocyanate in the urethane foam operations at the General Tire \& Rubber Company plant in Marion, Indiana.

IV. HEALTH HAZARD EVALUATION

A. Plant Process - Conditions of Use

The General Tire \& Rubber Company is engaged in the manufacture of molded urethane cushions for automobile seats and of bulk urethane foam for a variety of commercial uses.

Approximately nine employees per shift are employed at a urethane pouring and molding line in Department 446 (Molded Foam). This department operates three shifts per day. One employee is a compounder who is responsible for mixing batches of polyol. He makes the chemical additions which include PVC resins used as filler. The TDI and polyol are automatically mixed and dispensed at two pour heads on the production line. No employees are stationed at the pour heads unless there are mechanical breakdowns or other irregularities in the operation. The TDI-polyol mixture is injected into molds which then close and go through a battery of curing ovens where the urethane foaming and hardening takes place. The lids open as the molds emerge from the ovens, and two employees (pad pullers) remove the molded cushions manually. Two other pad pullers then spray a mold release wax into the empty molds. Four burlap apply operators insert fabric linings into the molds just prior to the foam injection at the pour heads.

Approximately six production workers are employed in the Slab Line in Department 447 where they operate and maintain machinery used for the production of bulk urethane foam. There is only one shift per day, but working hours frequently extend to 12 hours or more. A TDIpolyol mixture is dispensed from an automatic mixer and pour head onto a moving conveyor where it foams up to form a continuous loaf or slab of urethane foam. The line is enclosed on the sides up to a height of three or four feet; exhaust ventilation is provided overhead. 
Page 3 - Health. Hazard Evaluation Determination 74-118

B. Evaluation Design and Methods

On December 3-5, 1974, and January 7-9, 1975, NIOSH representatives, including industrial hygienists, physicians, and a nurse conducted environmental and medical investiqations of the facility. Environmental investications included samiling for airborne concentrations of toluene-2,4-diisocyanate (TDI), mold release wax, and free vinyl chloride monomer.

TDI sampling was performed on exposed employees in both areas during the day shift. Personal samples were collected by drawing air at a rate of one liter per minute through an impinger containing an absorbing solution. The impingers were attached to the workers' garments as close to the breathing zone as possible; air was pulled through the impingers by means of battery-powered pumps attached to the workers' belts. The impingers were later returned to the NIOSH analytical laboratories where the amount of TDI collected was measured colorimetrically.

The pad pullers in the Molded Foam area who also spray the mold release wax into the empty molds were sampled for exposure to aerosols of mold release wax. The samples were collected on 37-mm PVC filters in closed face cassettes; the quantity of 2 microcrystaliine wax collected was measured by fluorescence. ${ }^{2}$

The compounder in each of the two departments was sampled for exposure to free vinyl chloride monomer. Samples were colliected using charcoal tubes and miniature battery-powered pumps. The vinyl chloride collected was later desorbed with carbon disulfide and analyzed by gas chromatography employing a flame ionization detector. ${ }^{3}$ The limit of detection for the method was 0.5 microgram per sample.

The medical investigation of December 3-5 consisted of private interviews with a11 day-shift emplojees with direct TDI exposure and with other employees or former employees considered by the union to have health problems related to their work exposure to TDI at the plant. The company medical records of some of these employees were also reviewed at that time. A range of irritative symptoms related to TDI or a mold release wax exposure were reported by a number of those interviewed. For this reason, it was decided to carry out a more extensive study.

The final medical evaluation was carried out on January 8-9, 1975. Part of the investigation was concerned with evaluation for acute adverse effects developing over the work shift. Pre- and postshift testing was carried out on the day-shift production workers exposed to TDI and/or mold release wax. This included pre- and post- shift questionnaires and pulmonary function testing (PFT). Nine exposed workers were tested for pulmonary function. Addi- 
Page 4 - Health Hazard Evaluation Determination 74-118

tionally, an extensive questionnaire-interview was used to assess the respiratory and general health of the employees and to determine if pre-existing medical conditions were affected by recurrent acute exposure. Thirty production and five maintenance employees from the three snifts were administered the detailed questionnaire.

The prevalence of acute irritant symptoms which developed over the work shift and the relative frequencies of these symptoms were determined from the questionnaire - interview responses. The development of acute respiratory effects over the work shift was evaluated by comparing the pre- and post- shift pulmonary function testing (PFT) results in each individual and in each group of exposed smokers and of exposed ex.- and non-smokers.

The PFT parameters evaluated were forced expiratory volume in one second $\left(F E V_{1}, 0\right)$, forced vital capacity $(F V C), F E V_{1} .0 / F V C$, maximum mid-expiratory flow (IMEF $25-75$ ), and forced expiratory flow from 0.2 - 1.2 liters (FEF, 2-1,2)

c. Evaluation Criteria

1. Environmental Criteria

The criteria for assessment of acceptable environmentai levels of TDI and vinyl chioride are those recommended by MIOSH in 1973 and 1974. These recommendations are based on the most current state of knowledge concerning the toxicity of these substances and are designed to protect the health and safety of workers for an 8-hour day, 40-hour week over a normal working lifetime.

The NIOSH criteria document for TDI recommends that no worker's 8-hour exposure exceed a time-weighted average of more than 0.005 $\mathrm{ppm}$ rior an average level of more than $0.02 \mathrm{ppm}$ for any 20 -minute period. ${ }^{4}$ Vinyl chloride is recognized as a carcinogenic agent capable of inducing a rare form of liver cancer among occupationally exposed workers. NIOSH concluded that there is probably no threshold for carcinogenesis and that no safe level of exposure can be described. Consequentiy, NIOSH recommends that where any employee is exposed to measurable concentrations of vinyl chloride, as determined by the recommended sampling and analytical method, the employee should wear an air supplied respirator.

There is no environmental standard specific for mold release wax. The wax used at the plant during the period of this study was a water based emulsion of a microcrystalline wax consisting of a petroleum fraction which is primarily a mixture of linear and branched hydrocarbons with an average molecular weight of about 700. No toxic properties were known for this material. 
Page 5 - Health Hazard Evaluation Determination 74-118

\section{Medical Criteria}

The medical criteria used to determine a toxic response to the substances under investigation consist of the symptoms and signs which each substance produces when toxic exposure occurs. A brief review of the toxic effects of the substances of primary concern follows:

\section{a. Toluene $-2,4-$ diisocyanate (TDI)}

TDI is a strong irritant, especially to the eyes and upper and lower respiratory tract. If TDI Tiquid comes into contact with the eyes, severe conjunctival irritation occurs. With exposure to the vapor, burning or smarting in the eyes may be noted. Headache as well as gastrointestinal complaints of nausea, vomiting, and abdominal pain have been reported following inhalation of high concentrations of the vapor or aerosol. Of ail the adverse effects, the most notable are those involving the respiratory tract. Two specific effects have been noted:

(1) Primary irritancy. At sufficient concentrations of TDI, all exposed individuals may have respiratory effects such as burning of the nose and throat, a choking sensation, a dry or productive cough and general chest pain. These effects have sometimes been mistaken for a "cold" or upper respiratory tract infection. Exposure to higher concentrations of TDI can lead to severe irritation of the respiratory tract mimicking an asthmatic attack. Additional symptoms include headache, sleeplessness, ataxia, and euphoria.

(2) Allergic sensitization. When one has become "sensitized" to TDI, very small concentrations of TDI may elicit various symptoms. Coughing and shortness of breath, particularly during the night, as well as symptoms and signs of asthma may appear in sensitized individuals (such asthmatic reactions in a fe:y instances have been fatal).

A third type of effect of TDI on the respiratory tract is under study. This is the relationship between long-term exposure to TDI and cumulative impairment of lung function. Although some studies suggest that long-term exposure to non-irritating and non-sensitizing concentrations of TDI may impair lung function, further investigation is needed.

For purposes of this health hazard evaluation, an individual was judged to have an abnormal decrement in pulmonary function if any of his PFT parameters dropped by $10 \%$ or greater over the shift. In a similar manner, a group of workers was judged to have an abnormal decrement if its PFT values dropped by $10 \%$ or greater over the shift. 
Page 6 - Health Hazard Evaluation Determination 74-118

b. Vinyl chloride

Since environmental sampling revealed no exposures to vinyl chloride that were considered significant, no medical evaluation for health effects of vinyl chloride exposure was performed.

c. Mold release wax

Since no adverse health effects were known to be associated with microcrystalline wax, the medical evaluation was based upon symptoms prevalent within the pad pullers. Their symptomatology as a group was compared to that of other employees not exposed to mold release wax.

D. Evaluation Results and Discussion

1. Environmental Sampling Results

Seven of the nine employees on the day shift with the greatest potential TDI exposures in the Molded Foam area (Dept. 446) were sampled on January 8, 1975. The results of the samples are tabulated in Table 1. The personal exposures measured on that day were generally 10 per cent or less of the present recommended standards of NIOSH. This level of exposure is considered sufficiently low to protect employees from becoming sensitized to TDI and from experiencing primary irritancy. However, this level of exposure would not prevent adverse response in already sensitized workers, because available knowledge does not indicate any safe concentration for such bersone.

The four pad pullers on the day shift were sampled for exposure to mold release wax aerosols. The results of the samples are tabulated in Table 2. Charcoal tube samples were also collected to determine if any volatile substances were being emitted from the mold release wax which might cause irritation. However, no volatile substances were detected on any of these samples.

On the initial survey of December 4, 1974, the compounder in the Molded Foam area was sampled for exposure to free vinyl chloride monomer which might result from this work with PVC resins. The three consecutive samples covering the work shift measured levels of $0.3 \mathrm{ppm}, 0.2 \mathrm{ppm}$, and a non-detectable level. (The lower limit of detection by the method is $0.2 \mathrm{ppm}$.) Improvements in the local exhaust venilation system were made by the company between the initial survey and the follow-up survey of January 8, 1975. On the follow-up survey, both the compounder in the Molded Foam Area and in the slab area on the day shift were sampled for free vinyl chloride monomer exposure. Ho vinyl chloride was detected on any of the samples; the Timit of detection by the method used was 0.5 microgram of vinyl chloride per sample. Sampling data is presented in Table 3. At the end of the day, the compounder in the Slab area indicated that he had not mixed any batchs of polyol during the sampling periods; therefore, his measured exposure was essentially zero. However, observation of the mixing process and ventilation systems 
Page 7 - Health Hazard Eyaluation Determination 74-118

on other days indicated that the exposure was at least as well controlled as that in the Molded Foam area. Vinyt chloride is not thought to pose a health hazard to workers under the conditions observed during this evaluation.

The three employees considered to have the highest potential TDI exposures at the foam line in the Slab area (Dept. 447) were sampled on January 8, 1975 to measure their exposures to TDI. The sampling results are given in Table 4 . One of the nine samples indicated a concentration in excess of the NIOSH recommended standard of $0.005 \mathrm{ppm}$. A1though the 8-hour average exposures of a 11 individuals were less than the NIOSH recommended standard, the fact that the work day in this area frequently exceeds 12 hours means that the total daily dose of TDI is greater than that revealed by the 8-hour average alone. A 20-minute area sample taken over the foaming operation during start-up of the slab line indicated a concentration of $0.097 \mathrm{ppm}$, almost 5 times the recommended ceiling value. Employees are not normally exposed to these conditions except during start-up or during mechanical malfunction, and usually for shorter periods of time than 20 minutes. Although employees were sometimes observed wearing respirators during this period of high exposure, it was also observed that employees did not always wear respirators during these conditions. Since short-term high exposures are believed to be capable of inducing primary irritancy and allergic sensitization, it has been determined that the potential for adverse health effects to employees exists in this area and that further steps should be taken to correct and control exposures.

It should be noted that concentrations of all substances sampled during this evaluation were within current legal limits promulgated by the Occupational Safety and Health Administration of the U. S. Department of Labor.

\section{Medical Results}

Three (2 pad pullers and 1 burlap hanger) of the nine day-shift production employees who were evaluated pre- and post- shift noted the development of a dry or irritated throat over the work shift. One other individual (a pad pulTer) complained of a headache developing over the work shift. Pulmonary function results showed no evidence of significant acute change over the shift in any of the nine individuals. The group results are shown in Table 5.

Table 6 summarizes the questionnaire-interview findings in the workers exposed to TDI and mold release wax (MRW). The Table 6 data represent historical symptoms which workers experienced on the day of sampling or any previous time when the workers associated such symptoms with chemical exposures. Nearly all workers who have had symptoms associated with TDI related their symptoms to episodes in which they were exposed to pure, unreacted TDI. For the pad pullers and burlap appliers this occurred 
Page 8 - Health Hazard Evaluation Determination 74-118

when pure TDI was occasionally and accidentally injected into molds without polyol during equipment malfunction. For Slab Dept. employees an occasional equipment malfunction would also cause pure unreacted TDI to flow out of the nozzle, bringing on symptomatology. In Table 6 the association between symptoms and a chemical agent such as TDI or mold release wax is based solely upon the individual employee's indication of what he suspects as the cause of a specific symptom.

The medical findings indicate that employees have experienced principally acute irritative symptoms to TDI and mold release wax and show no present evidence of TDI allergic hypersensitivity. The nine production workers evaluated pre- and post- shift showed no evidence of acute airway obstruction developing over the shift, although several experienced mild irritative symptoms.

Review of the medical questionnaire revealed.several important findings. None of the 35 production or maintenance employees interviewed gave a history compatible with TDI respiratory hypersensitivity. Those individuals who noted episodes of chest congestion (cough, wheezing, shortness of breath, or chest tightness) described them occurring after malfunction of equipment or after a spill when TDI air concentrations were undoubtedly high. The symptoms were generally short-lived and did not recur when reexposed to TDI at the usual work area concentrations. Nevertheless, the fact that occasional exposures to presumabiy high concentrations of TDI take place emphasizes the need for appropriate protective and clean-up measures when these incidents occur. Hanaging equipment malfunction and TDI spills in this way will significantly reduce the risk of employees developing allergic hypersensitivity.

The effects of mold release wax were derived from the historical symptoms given by employees and shown in Table 6 .

The principal effect noted in employees exposed to mold release wax (MRW) was nose congestion or stuffiness. Eye, throat and upper respiratory irritation were also mentioned by exposed employees in a felv instances. The symptom of nose congestion occurred frequently among pad pullers. Some associated this symptom with rebound spray from the molds. The nose congestion may be due to an occlusive effect which the wax exerts when deposited in the nasopharynx. The nose congestion generally cleared after the employee left the plant and blew his nose a few times. However, in a few instances individuals with pre-existing sinus problems found their conditions greatly aggravated by their exposure.

\section{E. Recommendations}

1. Since the most severe TDI exposures at the plant seemed to occur during occasional episodes such as spills or mechanical malfunctions, the company management should institute better plans and procedures for controlling exposure of employees during such incidents. The emergency procedures should include the following provisions: 
Page 9 - Health Hazard Evaluation Determination 74-118

a. Only properly protected personnel should remain in the area where TDI has been accidentally released.

b. Adequate preparation and facilities for handling spills should be provided. These include suitable cleanup and disposal equipment.

c. The part VI of the NIOSH criteria document for TDI dealing with work practices should be used as a guideline for selection of equipment for cleanup and disposal.

d. Air-supplied masks or self-contained breathing apparatus must be used by workers in the area during these episodes.

e. TDI contaminated equipment should be washed and decontaminated before maintenance personnel begin repair or adjustment of equipment; or air-supplied masks or selfcontained breathing apparatus along with impervious gloves and footwear should be provided by the company and used by the workers during maintenance of TDI contaminated equipment.

2. The company should institute a program for educating all employees exposed to TDI of the hazards of exposure, proper work practices and emergency procedures.

a. Part I, Section 5 of the NIOSH criteria document for TDI should be used as a guide for the apprisal of employees of the hazards of TDI and relevant symptoms of overexposure. (copy enclosed)

b. All employees working in areas where TDI is regularly used should be instructed in procedures to be used in the event of spills or mechanical malfunctions, and should be instructed in the types of protective equipment to be used during both normal and emergency conditions. The use of these procedures and equipment in practice situations should be performed from time to time so that employees become and remain familiar with protective equipment and emergency procedures.

The location of safety showers, fountains, and eye baths must be made known to all employees. The need for immediate removal of TDI or reacting foams from the skin by thorough washing with soap and water should be impressed upon all workers. The necessity for prompt and thorough flushing of the eyes with water for 15 minutes in the event of contact should also be stressed.

3. Part I, Section 2 of the NIOSH criteria document for TDI should be used as a guide for the establishment of a medical program to include preplacement and annual medical examinations of a 71 workers reqularly exposed to TDI. One of the aspects of the annual medical examinations should be pulmonary function testing for forced vital capacity (FVC) and forced expiratory volume at one second $\left(\mathrm{FEV}_{1}, 0\right)$. 
Page 10 - Health Hazard Evaluation Determination 74-118

4. The four-minute area samples utilizing an on-site colorimetric reading, used by the company primarily in the past for TDI environmental monitoring, are considered too insensitive and inadequate for reliance as a method of environmental monitoring. The use of an on-site continuous TDI tape sampler by the company is desirable and should be continued. However, there is also a need to collect personal, breathing zone samples from workers in order to measure true exposure. The method recommended in the NIOSH criteria document for TDI should be utilized for measuring short-term exposures where the ceiling concentration may be exceeded. Longer-term samples taken successively at one liter per minute for one or two hours each would also be helpful for monitoring 8-hour average exposures.

5. In consideration of the higher manitude of TDI concentrations at the foam line in the SIab Dept. and the extended workino hours for the personnel in that area, further reduction of airborne concentrations by improved local exhaust ventilation is indicated. The more universal use of chemical cartridge respirators during tasks where short-term exposure is hiah may also be necessary. Part I, Section 4 of the NIOSH criteria document for TDI should be used as a guide to the selection, use and maintenance of NIOSH approved respirators suitable for use in TDI-contaminated atmospheres.

6. The exposure of pad pullers to mold release wax aersols was irritating to a number of the employees. The overhead exhaust ventilation used at the wax spraying stations at the time of the evaluation tended to draw the wax aerosols upward into the employees' breathing zones when they leaned over molds to spray the wax. Much of this problem could te corrected by installing down-draft ventilation which would pull the aerosols and rebound spray downward and away from the employees' breathing zones. Nose stuffiness might also be relieved if the company provided inexpensive, disposable filter masks for the pad pullers to wear during spraying.

\section{REFERENCES}

1. P\&CA Method No. 141, NIOSH Manual of Analytical Methods, HEW Publication No. (NIOSH) 75-121, 1974.

2. P\&CA Method No. 159, NIOSH Manual of Analytical Methods, HEW Publication No. (NIOSH) 75-121, 1974.

3. P\&CA Method No. 178, NIOSH Manual of Analytical Methods, HEW Publication No. (NIOSH) 75-727, 1974. 
Page 11 - Health Hazard Evaluation Determination 74-118

4. Criteria Document: Recommendations for an Occupational Exposure Standard for Toluene Diisocyanate, Publication IIo. HSM 73-711222, National Institute for Occupational Safety and Health, 1973.

5. NIOSH Recommended Standard for Occupational Exposure to Vinyl Chloride, National Institute for Occupational Safety and Health, Cincinnati, Ohio, 1974.

VI. AUTHORSHIP AND ACKNOWLEDGMENTS

Report Prepared by $\quad$ C. Paul Roper, Jr.
Industrial Hygienist
Hazard Evaluation Services Branch
Cincinnati, Ohio
John W. Cromer, Jr., M.D.
Medical Officer
Medical Services Branch
Cincinnati, Ohio $\quad \begin{aligned} & \text { Jerome P. Flesch } \\ & \text { Chief } \\ & \text { Hazard Evaluation Services Branch } \\ & \text { Cincinnati, Ohio } \\ & \text { Eriginating Office } \quad \text { Nurse Philbin } \\ & \text { Medical Services Branch } \\ & \text { Cincinnati, Ohio } \\ & \text { William Brush } \\ & \text { Medical Officer } \\ & \text { Medical Services Branch } \\ & \text { Cincinnati, Ohio } \\ & \text { Dawn M. Gilles } \\ & \text { Industrial Hygienist } \\ & \text { Hazard Evaluation Services Branch } \\ & \text { Cincinnati, Ohio } \\ & \text { Robert E. Rosensteel } \\ & \text { Industrial Hygienist } \\ & \text { Hazard Evaluation Services Branch } \\ & \text { Cincinnati, Ohio }\end{aligned}$


Page 12 - Health Hazard Evaluation Determination 74-118

Acknowledgments : Raymond L. Ruhe

Industrial Hygienist

Hazard Evaluation Services Branch

Cincinnati, Ohio

Anthony W. Smal1wood

Chemist

Physical and Chenical Analysis Branch

Cincinnati, Ohio

Ceola H. Moore

Physical Science Aide

Physical and Chemical Analysis Branch

Cincinnati, Ohio 


\section{Table 1}

RESULTS OF ENVIRONMENTAL SAMPLING FOR TDI IN DEPT. 446 - MOLDED FOAM

(Persona ${ }^{7}$, breathing-zone samples)

January 8,1975

\begin{tabular}{|c|c|c|c|c|}
\hline Job Title & Sample No. & Sampling Period & $\frac{\text { Volume Sampled }}{\text { (1 iters) }}$ & $\frac{\text { TDI Concentration }}{(\mathrm{PPP})}$ \\
\hline Compounder & $\begin{array}{l}35 \\
35 A \\
35 B\end{array}$ & $\begin{array}{r}6: 42-9: 16 \\
9: 16-12: 20 \\
12: 20-3: 06\end{array}$ & $\begin{array}{l}154 \\
184 \\
166\end{array}$ & $\begin{array}{r}0.0006 \\
N .0 . * \\
0.0003\end{array}$ \\
\hline Pad Puller A & $\begin{array}{l}36 \\
36 \mathrm{~A} \\
36 \mathrm{~B}\end{array}$ & $\begin{array}{r}6: 47-9: 23 \\
9: 23-12: 30 \\
12: 30-3: 04\end{array}$ & $\begin{array}{l}156 \\
187 \\
154\end{array}$ & $\begin{array}{c}0.0006 \\
\text { N.D. } \\
\text { N.D. }\end{array}$ \\
\hline Pad Puller B & $\begin{array}{l}38 \\
38 \mathrm{~A} \\
38 \mathrm{~B}\end{array}$ & $\begin{array}{r}6: 54-9: 22 \\
9: 22-12: 24 \\
12: 24-3: 10\end{array}$ & $\begin{array}{l}348 \\
182 \\
166\end{array}$ & $\begin{array}{l}0.0005 \\
0.0005 \\
0.0017\end{array}$ \\
\hline Pad Puller C & $\begin{array}{l}41 \\
41 A \\
41 B\end{array}$ & $\begin{array}{r}7: 15-9: 27 \\
9: 27-12: 38 \\
12: 38-3: 33\end{array}$ & $\begin{array}{l}132 \\
191 \\
175\end{array}$ & $\begin{array}{l}0.0022 \\
0.0004 \\
0.0001\end{array}$ \\
\hline Pad Puller D & $\begin{array}{l}43 \\
43 A \\
43 B\end{array}$ & $\begin{array}{r}7: 44-9: 26 \\
9: 26-12: 35 \\
12: 35-3: 23\end{array}$ & $\begin{array}{l}102 \\
189 \\
168\end{array}$ & $\begin{array}{l}0.0007 \\
0.0001 \\
0.0003\end{array}$ \\
\hline Burlap Apply A & $\begin{array}{l}37 \\
37 \mathrm{~A} \\
37 \mathrm{~B}\end{array}$ & $\begin{array}{r}6: 50-9: 11 \\
9: 11-12: 41 \\
12: 41-3: 05\end{array}$ & $\begin{array}{l}141 \\
210 \\
144\end{array}$ & $\begin{array}{l}0.0001 \\
\text { N.D. } \\
0.0001\end{array}$ \\
\hline Burlap Apply B & $\begin{array}{l}39 \\
39 A \\
39 B\end{array}$ & $\begin{array}{r}7: 00-9: 10 \\
9: 10-12: 18 \\
12: 18-3: 16\end{array}$ & $\begin{array}{l}130 \\
188 \\
178\end{array}$ & $\begin{array}{l}0.0009 \\
0.0002 \\
0.0003\end{array}$ \\
\hline
\end{tabular}

* N.D. means "none detected". For the purposes of this study, the lower limit of detection was considered to be 0.0001 PPM. 


\section{Table 2}

RESULTS OF ENVIRONMENTAL SAMPLES FOR MOLD RELEASE WAX IN gEPT. 446 - MOLDED FOAM (Personal, breathina-zone samples)

GENERAL TIRE \& RUBBER COMPANY

MARION, INDIANA

January 8, 1975

\begin{tabular}{|c|c|c|c|c|}
\hline Job Title & Sample No. & Sampling Period & $\frac{\text { Volume Sampled }}{\text { (1iters) }}$ & $\frac{\text { Concentration }}{\text { (Mg/cu.m.) }}$ \\
\hline Pad Puller A & $\begin{array}{l}\text { PVC-11 } \\
\text { PVC-2 }\end{array}$ & $\begin{array}{r}6: 45-72: 30 \\
12: 30-3: 04\end{array}$ & $\begin{array}{l}690 \\
308\end{array}$ & $\begin{array}{l}4.78 \\
1.07\end{array}$ \\
\hline Pad Puller B & $\begin{array}{l}\text { PVC-8 } \\
\text { PVC-4 }\end{array}$ & $\begin{array}{r}6: 55-12: 24 \\
12: 24-3: 10\end{array}$ & $\begin{array}{l}659 \\
332\end{array}$ & $\begin{array}{l}1.84 \\
2.23\end{array}$ \\
\hline Pad Puller C & $\begin{array}{l}\text { PVC-10 } \\
\text { PVC-3 }\end{array}$ & $\begin{array}{r}7: 18-12: 38 \\
12: 38-3: 33\end{array}$ & $\begin{array}{l}640 \\
350\end{array}$ & $\begin{array}{l}8.61 \\
1.40\end{array}$ \\
\hline Pad Puller D & $\begin{array}{l}\text { PVC-7 } \\
\text { PVC-5 }\end{array}$ & $\begin{array}{r}7: 45-12: 35 \\
12: 35-3: 23\end{array}$ & $\begin{array}{l}580 \\
336\end{array}$ & $\begin{array}{l}2.19 \\
3.60\end{array}$ \\
\hline
\end{tabular}


Table 3

RESULTS OF ENVIRONMENTAL SAMPLES FOR VINYL CHLORIDE (Personal, breathing-zone samples)

GENERAL TIRE \& PUBBER COMPANY

MARION, INDIANA

January 8, 1975

Job Title

Sample No.

Sampling Period

$\frac{\text { Sample Volume }}{\text { (liters) }} \frac{\text { Concentration }}{\text { (PPM) }}$

Compounder

(Moided Foam)

CT -30

CT -47

$6: 40-9: 15$

$9: 15-12: 20$

CT -49

$12: 21-3: 06$

13.2

51.1

9.46

*N.D.

N.D.

N.D.

Compounder

CT -45

$7: 47-9: 33$

6.54

$9: 33-3: 23$

$14 . ?$

N.D.

CT -48

The lower limit of detection by the method

*N.D. means "none detected". was $0.5 \mathrm{microgram} / \mathrm{saniple.}$ 


\section{Table 4}

RESULTS OF ENVIRONWENTAL SAMPLES FOR TDI IN DEPT. 447 - SLAB AREA
(Persona1, breathing-zone samples)

GENERAL TIRE \& RUBBER COMPANY

MARION, INDIANA

January 8, 1975

Job Title

Sample No.

Sampling Period

Volume Sampled

$\frac{\text { TDI Concentration }}{\text { (PPM) }}$

Paper Wind-Up

40

$40 \mathrm{~A}$

$7: 14-9: 31$

$9: 31-1: 05$

$1: 05-3: 37$

137

214

152

0.0031

$40 B$

$7: 20-9: 36$

$9: 36-1: 03$

$1: 03-3: 45$

136

207

0.0017

42

$42 B$

162

0.0034

Compounder

44
$44 A$
$44 B$

$7: 47-9: 34$

107

0.0024

0.0024

$0.00 \mathrm{C} 3$

$44 \mathrm{~A}$
$44 \mathrm{~B}$

$9: 34-1: 00$

206

0.0008

$1: 00-3: 29$

149

0.0007

0.0070 
DIFFERENCE BETWEEN PRE- AND POST-SHIFT MEANS

FOR PULMONARY FUNCTION TESTING

\section{Pre-Shift}

Mean Value
Post-Shift

Mean Value

$\mathrm{FEV}_{1.0}(\mathrm{~L} / \mathrm{sec})$

Exposed - smokers

3.92

3.82

Exposed - ex and non smokers

3.95

3.97

FVC (L)

Exposed - smokers

4.88

4.82

Exposed - ex and non smokers

4.99

4.88

$\mathrm{FEV}_{7} / \mathrm{FVC}(\%)$

Exposed - smokers

81.0

81.7

Exposed - ex and non smokers

83.2

82.8

MMEF $_{25-75}(\mathrm{~L} / \mathrm{sec})$

Exposed - smokers

3.63

Exposed - ex and non smokers

4.12

3.85

FEF.2-1.2 (L/sec)

Exposed - smokers

7.43

4.18

Exposed - ex and non smokers

7.42

7.70

9.94 
Table 6

HISTORICAL SYMPTOMATOLOGY IN EXPOSED EMPLOYEES

No. Employees Evaluated

JOB DESCRIPTION

\begin{tabular}{|c|c|c|c|c|}
\hline $\begin{array}{l}\text { Foam } \\
\text { Line }\end{array}$ & $\begin{array}{c}\text { Pad } \\
\text { Pullers }\end{array}$ & $\begin{array}{c}\text { Burlap } \\
\text { Appliers }\end{array}$ & Maintenance & $\begin{array}{l}\text { Grand } \\
\text { Total }\end{array}$ \\
\hline 7 & 13 & 10 & 5 & 35 \\
\hline 9.5 & 3.3 & 4.6 & 4.6 & - \\
\hline 1 & 2 & 0 & 0 & 3 \\
\hline
\end{tabular}

No. empioyees with job-related symptoms:

(1) Dry or sore throat associated with:
(a) TDI
(b) $\mathrm{MRW}$
(c) "Chemical fumes"

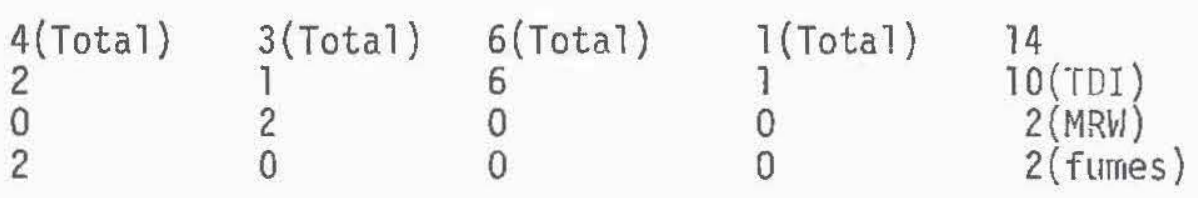

(2) Eye irritation associated with:
(a) TDI
(b) MRW
(c) "Chemical fumes"

4 (Total) 12 (Total)

27

0

2

7
3
2

$7(\operatorname{Tota} 1)$
7
0
0

$1(\operatorname{Tota} 1)$
1
0
0

24

17 (TDI)

3 (MRW)

4(fumes)

(3) Nose congestion associated with:
(a) TDI
(b) $\mathrm{MRW}$
(c) "Chemical fumes"

$\begin{array}{ll}1 \text { (Tota } 1) & 8 \text { (Total) } \\ 1 & 0 \\ 0 & 7 \\ 0 & 1\end{array}$

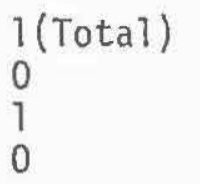

1 (Tota 1$)$
1
0
0

11

\section{(4) Chest congestion} associated with:
(a) TDI
(b) MRW
(c) "Chemical fumes"

$\begin{array}{ll}1 \text { (Total) } & 10(\text { Tota } 1) \\ 1 & 5 \\ 0 & 3 \\ 0 & 2\end{array}$

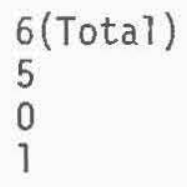

2 (Total)
2
0
0

19

13(TDI) $3(\mathrm{MRW})$ 3 (fumes)

Vo. employees who were:
(1) Smokers
(2) Ex- and non-smokers
4
6
19

$\begin{array}{ll}3 & 19 \\ 2 & 15\end{array}$

